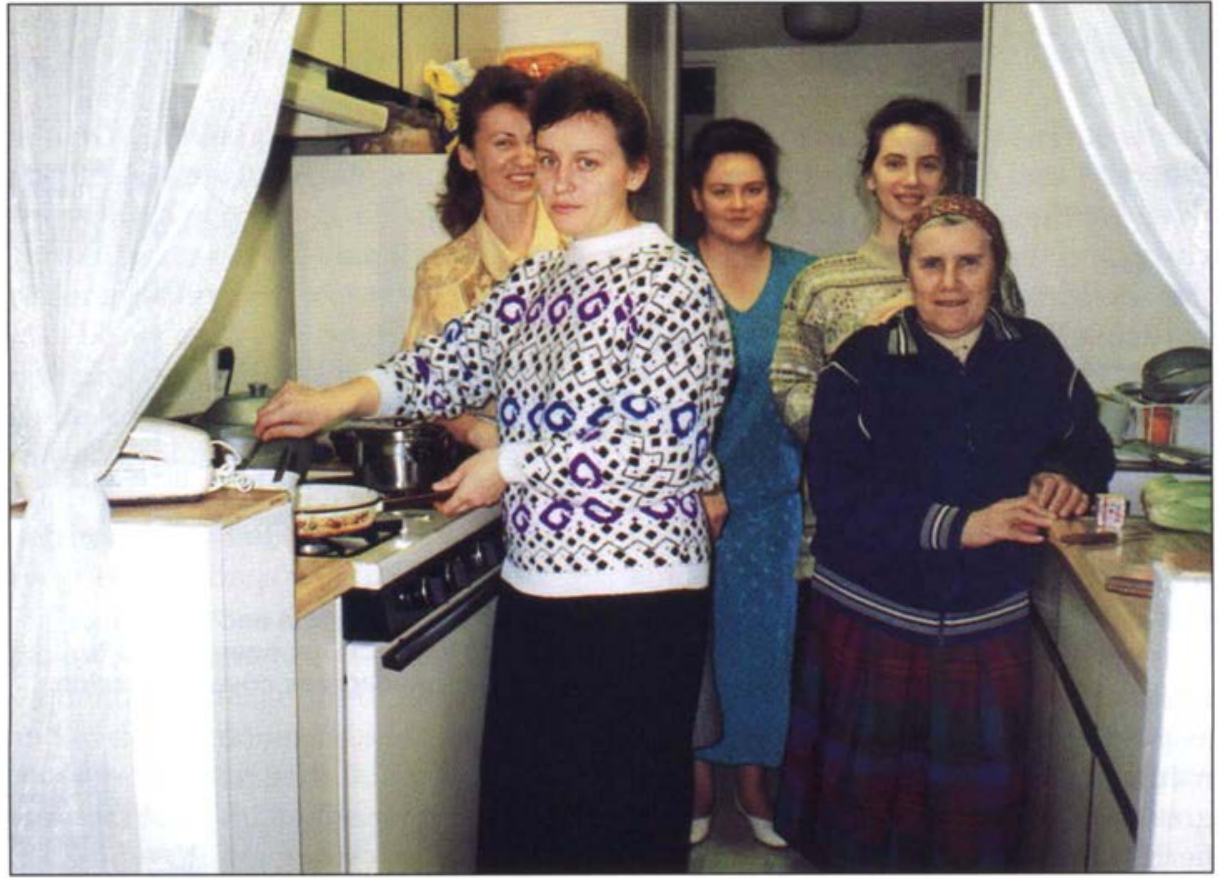

Food preparation can be a celebration for many women from the former Soviet Union, who enjoy their role as gatekeepers of dietary traditions.

\section{Refugees of former Soviet Union slowly adopt U.S. diet}

\author{
Eunice Romero-Gwynn a Yvonne Nicholson a Douglas Gwynn \\ Holly Raynard \ Nancy Kors \ Peggy Agron \ Jan Fleming \\ Lakshmi Sreenivasan
}

\begin{abstract}
The diet of refugees from the former Soviet Union living in Sacramento is characterized by a high reliance on grains, meats and dairy foods. While consumption of vegetables and fruits is increasing in Sacramento, it still appears to be very low. High-fat foods and salt-preserved foods are major components of the diet. Families from the former Soviet Union living in Sacramento have not yet made major changes in their food preparations and meal patterns. However, they are adopting a variety of new foods into their traditional meals. While dietary acculturation among adults appears to be low, school-age children are rapidly becoming acculturated and are consuming American fast foods and snacks.
\end{abstract}

ter of 1994. The two provider focus groups included 16 employees from Sacramento agencies that provide services to individuals from the FSU. The six refugee focus groups included 35 adult refugees (mostly female) selected by six local agencies. We wanted people who had come to the United States after the fall of the Communist regime and who were knowledgeable of other people in the refugee community. In addition, a panel of key members of the FSU refugee community, selected by the researchers, provided more than 20 consultations during the study. A matrix of consistent responses obtained among the focus groups was used to assess the validity of the data. Additional information was acquired during visits to homes of refugees, visits to newly established Russian grocery stores and participation in religious celebrations (RomeroGwynn et al. 1994).

\section{FSU refugees in Sacramento}

Most refugees from the FSU who settled in Sacramento prior to 1994 came from farming communities or small towns in the Slavic states or from the former Russian Central Asia region. The migration pattern to other sites in California appears to be different.

The typical refugee family in Sacramento is large and often extended. It consists of a husband, wife, children (as many as 12 reported) and, very often, parents of one or both spouses. The husband and wife have at least an elementary education, and many of them hold advanced university degrees. Some of the refugees participating in our focus group were physicians, dentists, pharmacists and engineers. Employment of the participants, at the time of this study, was very low. Poor English language skills appeared to be the main limiting factor.

\section{Food preferences}

The diet of people in the FSU has been influenced by geographic location and numerous political and historical events (Blanksteen 1974,

Deutsch 1986, Gould-Marks 1963, Lih 1990). Invaders and traders from Asia and the Middle East introduced a variety of foods, as well as different food preparation and preservation tech- 
niques. Neighboring countries, particularly Sweden, Germany, Poland, France and Greece, have influenced the diet in the FSU at different times and to different degrees. The French influence on the Russian diet was significant in the 18th century, when Catherine II encouraged the hiring of French cooks (Toomore 1992). Fasting advocated by the Orthodox Church (which calls for dietary restrictions to be practiced on more than 100 days per year) appears to have also helped shape the dietary traditions in the FSU (Smith and Christian 1984, Toomore 1992).

Grains. The major food staples of the FSU are grains, especially wheat, originally introduced from the Middle East, and rice, introduced from Asia. Barley, buckwheat, millet, oats and groats are also consumed.

Chamberlain's comment that people from the FSU "can live by bread alone" (1982) underscores the key role of bread in their diet. Traditional bread is the food most missed by refugees in the markets in Sacramento. Many women prepare their breads at home and often sell them to other families. They are fond of freshly baked, heavy, coarse bread, often made from whole grain flour. In addition to bread, wheat flour is used to prepare a variety of foods made with batter or dough. Dumplings, different types of pancakes, and ravioli-like foods are very important in the diet. Traditional foods based on wheat flour include blini, pelmeni, pirog, piroshki, and vareniki (see Glossary, p. 26). Kasha is often prepared with whole grains (buckwheat, wheat or oats) and milk. While refugees in Sacramento appear to be preserving many of their traditional grain-based dishes, American breakfast cereals are consumed in place of traditional kasha.

Vegetables. The long winters in the FSU limit the availability of fresh vegetables and fruits. Pickling, a practice introduced to Russia by Asian invaders and traders, has been crucial in maintaining a supply of basic vegetables yearround (Norman 1967). Pickled vegetables - including cabbage, cucumbers and mushrooms are among favorite foods in the FSU. Other commonly consumed vegetables include beets, carrots and potatoes. Vegetables are primarily consumed in soups, stews and rice pilafs; they can also be fried and used as stuffing for pirog, piroshki and other pastries (Uvezian 1976, Sacharow 1989).

Pickling vegetables is a common practice among refugees in Sacramento. Broccoli, cauliflower, lettuce, red cabbage and zucchini are vegetables that refugees rarely consumed before immigration but consume in California. Frozen vegetables are gaining acceptance.

Fruits. Many of the focus-group participants praised the availability of fruits in American markets. Buying fresh fruits in winter was an amazing experience for them. A participant from Tajikistan told the group, "I bought 6 kilos of oranges yesterday while it was close to freezing outside the market." Another participant said, "I have eaten more fruits in 6 months in Sacramento than in 28 years in Russia."

Strawberries, berries, apples, pears, watermelons and peaches were the most common fruits consumed in the FSU. Fresh fruits were eaten during the growing season and fruit preserves (jam, jelly and cooked fruit) were consumed throughout the year. Cooked fruit-based drinks (compote and kisel) were also common ways to use fruits through the year. They continue to consume traditional fruits and fruit preserves in Sacramento. "New" fruits, or fruits rarely consumed before immigration, include pineapple, banana, kiwifruit, mangoes and citrus fruits. Frozen fruit juice is also being used.

Dairy foods. "Russians have a milk complex...; they drink all the milk they can get and they like it rich," says Kropotkin (1993). People from the FSU consume large amounts of fresh milk, homemade soured milk, kefir, buttermilk, soft cheese, sour cream and butter. Yogurt and ice cream are also consumed often. Fresh milk is usually boiled, then cooled and consumed plain as a beverage or prepared with grains in kasha. Soured milk is consumed plain or it is used in preparing a cold soup during the summer.

Kropotkin's assertion that "no wellfurnished supper table is complete without a generous cheese supply"
(1993) illustrates the Russian predilection for cheese. Common Russian cheeses include one similar to cottage cheese and a semisoft cheese similar to feta cheese. While some families in Sacramento continue to prepare some of their traditional cheeses at home, many are buying American cheeses such as jack, mozzarella and some Mexican cheeses.

According to respondents, refugees have greatly increased their consumption of all types of dairy foods in Sacramento. Most of them prefer whole milk, although some are buying lowfat milk. Although most people had eaten commercially produced yogurt and ice cream in the FSU, they often expressed amazement at the variety available in the United States. A new way of consuming cheese is in pizza, which is popular among both adults and children.

Meats and fish. Most participants expressed a strong preference for fish and a variety of fresh and preserved meats. Fish is consumed fresh, salted and smoked or salted and dried. The participants' consumption of fish has declined since they arrived in Sacramento, however, owing to the lack of Russian fish species and the high price of American fish.

Goose (fresh and canned) was widely consumed in the FSU, whereas chicken is the most popular poultry consumed in Sacramento. It is prepared in many ways, including fried, cooked in soups or stews, and baked. Beef is usually minced and used in the stuffing for vegetables and pastries, and in a hamburgerlike dish (katleta). Beef is also used in stews, cooked in rice pilaf (plov), fried or creamed with sour cream. Pork and lamb are also well liked.

Several participants expressed a great fondness for salami. In addition to salami, other cold cuts and sausages are frequently enjoyed. Hot dogs, pastrami, bologna, salami and ham are eaten frequently in potato salad and other dishes.

Eggs are widely consumed. These are fried, prepared in omelets, hardboiled, and stuffed, as in Russianstyle deviled eggs. Eggs are also included in breads and pastries. Raw

(continued on page 27) 


\section{Glossary of selected foods and dishes}

\author{
(Alternative spellings are indicated in parentheses)
}

Blinchiki. Rolled blini, often filled with cheese or ground-meat-based filling. See also nalistniki.

Blini and oladi. Russian yeast pancakes. These can be eaten with jam or with fish or cold cuts. Blini are dressed with butter and/or sour cream. Butter and buttermilk are often used in preparing the batter for oladi.

Buckwheat. Cereal grain used in the preparation of several types of kasha. Buckwheat flour is also used in breads and pancakes.

Compote. Fruit-

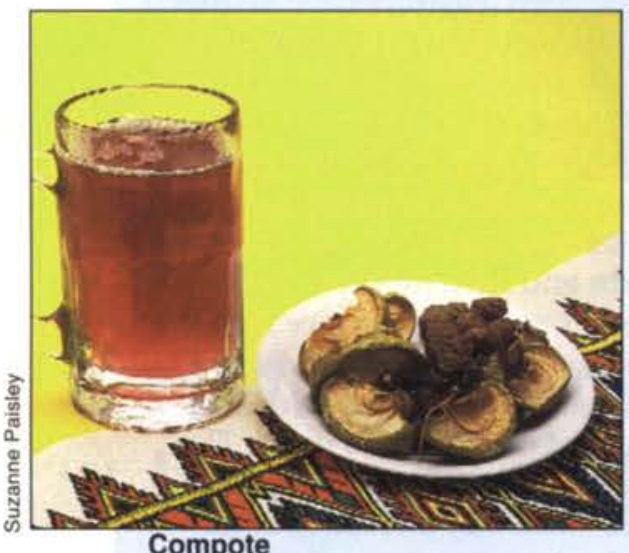

based beverage prepared from cooked fresh or dried fruits.

Kasha. Porridge made from buckwheat, cracked wheat, rice, pasta, oats or other grains. It can be consumed as a breakfast cereal (sweetened) or as a meal dish (unsweetened).

Kefir. Thick buttermilk. It is usually prepared from milk or dairy cream and consumed at breakfast.

Kisel. Cooked fruit, puréed and thickened with cornstarch. Milk or cream is poured on it. Fruits used include cranberries, currants, strawberries, raspberries and combinations of berries.

Kvas (kvass). Beverage made from grains or rye bread. Kvas is also used as stock for cold soups.

Nalistniki (nalysniki). Pancakes rolled and stuffed with cheese.

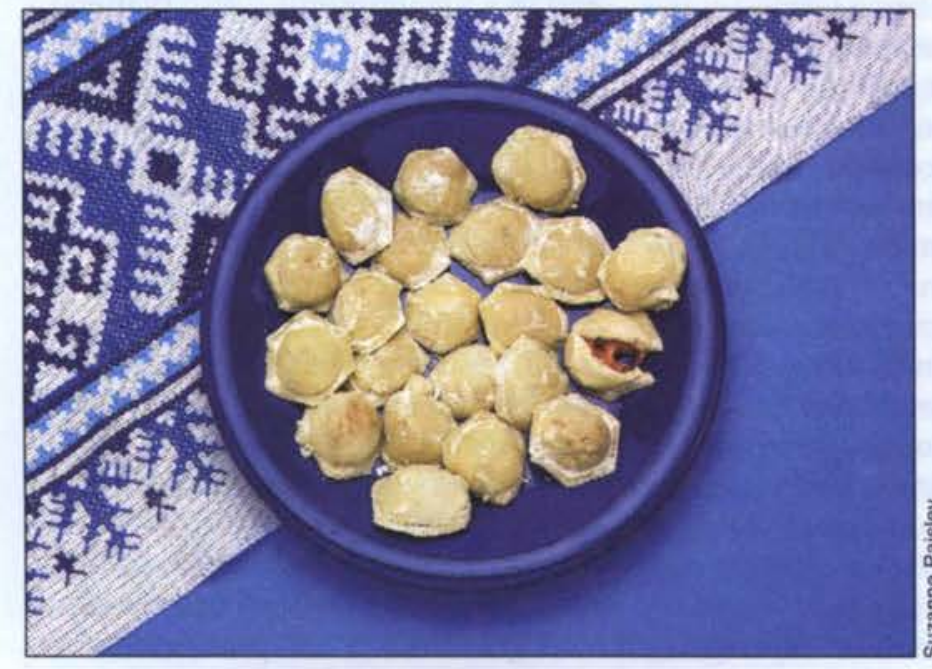

Pelmeni

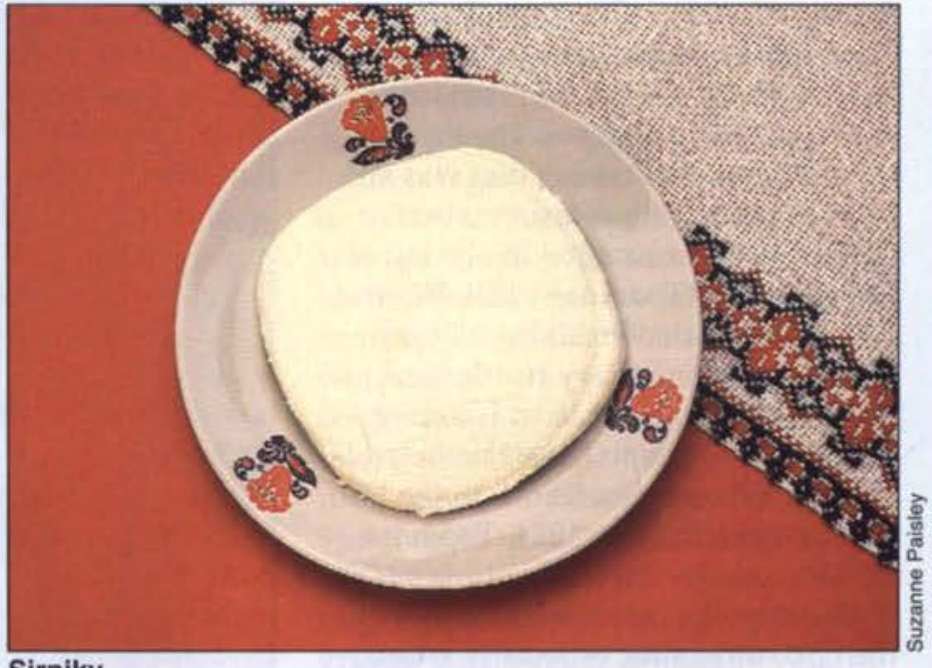

Sirniky

Pelmeni. Ravioli-like pastries filled with meat. Pelmeni are served with melted butter and/or sour cream. They are often served sprinkled with sugar and dunked in fruit syrup. Pelmeni can also be filled with mashed potatoes, cheese or fruits, in which case they are called vareniki.

Pirog. Rectangular or oval-shaped pie filled with one or more of the following fillings and baked: meat and eggs, braised cabbage, rice, and mushrooms. Served as a main dish at lunch or supper.

Piroshki (pirozhki). Small pirog-like pastries filled with meat, mushrooms, fish, cheese and/or cabbage. Piroshki can be baked or fried.

Plov. Rice pilaf often prepared with meats, onions and carrots. It is a very common dish in the Caucasus and the Central Asian regions.

\section{Prosto-} kvasha.

Soured milk, which is prepared by leaving raw milk to ferment in a warm place for several hours.

Salo. Raw pork fat, often consumed with bread; it is also

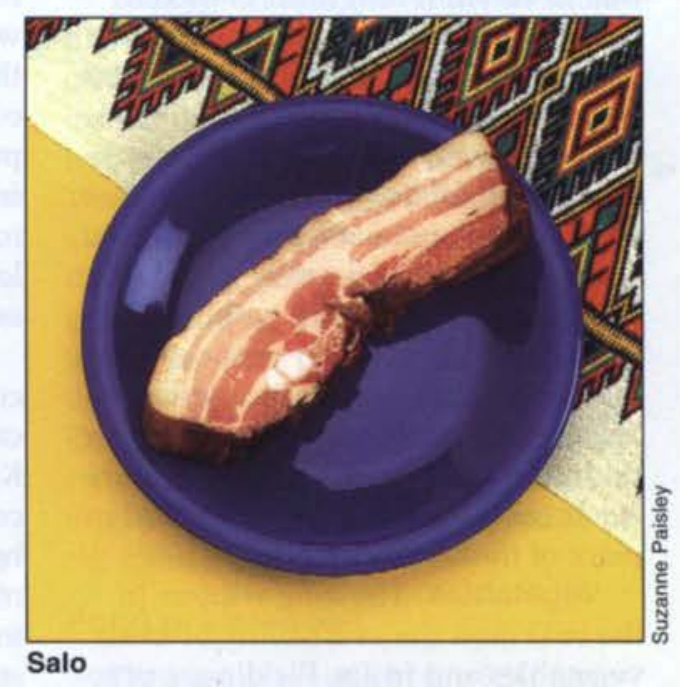
used in dressings for potatoes and other dishes.

Sirniky (tvorozhniky). Pancake-shaped cheese coated with flour and slightly fried. Served at breakfast, usually topped with sour cream and sugar.

Vareniki. Pastries (dumplinglike) filled with mashed potatoes, fruits, cheese or sauerkraut. Originally from the Ukraine. See pelmeni. 
(continued from page 25)

eggs are also consumed. Health educators are advised to discourage this practice, particularly for infants, children, pregnant women and the elderly.

Fat sources. The refugees' diet can be very high in fat. Butter, margarine and vegetable oil are extensively used in cooking. Sour cream and mayonnaise, consumed almost daily, are used in dressings and toppings. Raw pork fat, called salo, is often consumed sliced on bread; it is also minced, fried and used as dressing for potatoes and other foods. Refugees rarely trim fat from poultry or other meats. They said their consumption of fat-rich foods has greatly increased in Sacramento. Families are buying large amounts of the fats they were already familiar with. In our home visits, we always observed commercial-sized containers of margarine, butter and sour cream. Commercial salad dressing, nondairy creamer and whipping cream are new sources of fat they have incorporated into their diets in Sacramento.

Sweets. Participants expressed a love for sugar-rich foods. Preparation of desserts, cakes and fruit jam and jelly are traditional activities that continue to be practiced in Sacramento. Jams and jellies are extensively used on breads, as filling or topping for pastries and as a sweetener for tea.

Sugar is commonly used to sweeten cold and hot beverages. Tea, the most common hot beverage, is often sweetened with sugar or sipped through a sugar cube (Chamberlain 1982). Refugee families in Sacramento are consuming more tea and eating more desserts than they did in the FSU so their sugar consumption has probably increased as well. Many adults and school-age children quickly adopted soft drinks in place of the traditional homemade beverages, kisel and compote. Large bottles of soft drinks were often observed as part of the table setting at family celebrations.

\section{Perceptions of U.S. diet}

Refugees' perceptions of diet and the availability of food in the United States are reflected in the following sample of their statements:
"Americans have a large selection of foods, but they also have a lot of dry foods, like chips."

"In Sacramento, we can buy fruits and vegetables that were not available in Russia."

"When we arrived here 3 months ago during the winter, there were fresh fruits and vegetables in the market!"

Most refugees expressed pride in their traditional diet and in their food preparation skills:

"In our homeland, we make things ourselves. We bake our own bread."

"We like to eat soups; we use more fluids in our meals. Maybe here, we are eating too little soup."

"I have noticed that they [Americans] eat noncooked things for meals, like sandwiches; Americans do not eat soups."

These statements reflect the high value the refugees placed on fresh foods, foods prepared at home and moist foods, particularly soups. To Russians, soup symbolizes family, closeness and security, as reflected in the Russian proverb: "A house without soup is an unlucky house" (Sacharow 1989).

\section{Diet and life cycle}

Pregnant women. Most pregnant refugee women do not significantly change their diet during pregnancy. Most women do not consume alcoholic beverages or coffee and do not smoke cigarettes during pregnancy. Some participants indicated that doctors in the FSU favor limiting weight gain during pregnancy. Restriction of meats, breads and sweets may be recommended by doctors. Other participants commented that doctors in Sacramento "say nothing about foods to eat during pregnancy," so "we do what doctors advised in Russia."

Infants. Breastfeeding for about 1 year is the traditional practice in the FSU. The refugees practiced breastfeeding in California, but for a shorter period of time. The following comments were made during focus groups:

"In Russia, doctors don't recommend formula; I breastfed my baby for 1 year."
"We did have formula in my homeland, but we prefer breastfeeding."

"Russian women breastfeed for as long as possible. There is no reason not to. The longer the better."

"In Sacramento, I breastfed my baby for 4 months."

"I did not have enough milk [in Sacramento], so I breastfed for only 3 months."

"Not having enough breast milk" is a syndrome associated with inadequate breastfeeding techniques used by the mother.

Early feeding of cow's milk and other supplementary foods to infants was identified by participants as a common practice. However, comments by refugees did not consistently identify whether this was a traditional or newly adopted practice.

School-age children. Refugee mothers are especially concerned about the foods their children eat in school. They perceive "school foods" to be of poor nutritional quality. They feel that a nutritious meal should include soup. The following statements illustrate their concern about their children's nutrition:

"My children eat two meals in the school and when they come home they don't like our foods."

"At school they feed children too many dry foods like hamburgers and pizza, but no soup."

"They also feed children cold milk; we feed them warm milk, especially if they have a sore throat."

"The foods that our children are eating in the school are not moist; they are learning to eat dry foods!"

Their concern regarding soup has some validity. Traditional soup can be a meal in itself, often including whole grains, vegetables and meats. The high value placed on moist foods (that is, soups and other traditional foods) suggests the need to further explore beliefs of hot-cold and dry-wet ideologies among refugees from the FSU.

Elderly. Providers from local agencies reported that chronic diseases particularly hypertension, obesity, heart disease, liver disease and diabetes - were major problems among the elderly refugees. This was consistent 
with information given by two Russian doctors in our focus groups. Many refugees expressed satisfaction that in Sacramento they were able to provide enough food and medicine for their parents.

Based on our observations during home visits, a decline in physical activity can be a major health risk for the refugees from the FSU. Most families have moved from heavy farm labor to a very sedentary life in small apartments in Sacramento.

\section{Dietary recommendations}

The diet of new refugees from the former Soviet Union who have settled in Sacramento is varied. It is based on grain-based foods and dishes; a variety of dairy foods, meats, eggs, preserved vegetables and fruits; and to a lesser extent, fresh fruits and vegetables.

At the time of this study, the traditional diet had not changed significantly. Basic family food preparations, meal schedules and overall composition of the diet have not changed significantly. The most significant dietary change reported is the consumption of familiar foods in larger quantities and with greater frequency. Numerous food items have been adopted and integrated into traditional meals. New foods adopted by refugees include new types of cheese, ready-to-eat breakfast cereals, several vegetables and fruits, soft drinks, chips, pizza, salad dressing, whipping cream and nondairy cream. Several traditional foods - buckwheat, Russian bread, several varieties of Russian fish and kvas - are eaten less often or not at all because of their unavailability or high price in Sacramento. Other foods are being replaced by new American alternatives. For example, kasha is being replaced by ready-to-eat breakfast cereals, and homemade beverages such as kisel and compote have been largely replaced by commercial soft drinks.

Overall, refugees expressed the feeling that their diet has largely improved in Sacramento because of greater access to a large and diverse food supply in U.S. grocery stores. However, we identified the following areas of nutrition and health concerns: increased consumption of traditional and new sources of fats, new sources of sugars, and high consumption of sodium-rich foods, such as saltpreserved fish, cold cuts and pickled vegetables. We also recognized the need to promote greater consumption of fresh vegetables and fruits. Healthful dietary practices that should be supported include the preference for whole grains and vegetable soups and the high value placed on breastfeeding infants. Increasing refugees' awareness of the value of physical activity for good health is of primary importance. Specific recommendations for nutrition and health educators can be found in other sources (RomeroGwynn et al. 1994, Romero-Gwynn et al. 1997.) Larger studies are needed to further assess dietary ideologies and practices, nutrition-related chronic diseases, dental health and physical activity among refugees from the former Soviet Union.

E. Romero-Gwynn is Associate Clinical Professor, Division of International Health and Cross-cultural Medicine, School of Medicine, UC San Diego (Emeritus Nutrition Specialist, Department of Nutrition, UC Davis); $Y$. Nicholson is Family and Consumer Science Advisor, UC Cooperative Extension, Sacramento County; D. Gwynn is Codirector MEDGO International, Escondido; H. Raynard is Graduate Student, Slavic Studies, UCLA; N. Kors is dietitian in private practice, Sacramento; $P$. Agron is Dietitian, Health Education Council, Project Lean, Sacramento; J. Fleming is Dental Hygienist, County Department of Health Services, Sacramento; and L. Sreenivasan is EFNEP Program Supervisor, UC Cooperative Extension, Sacramento County.

Special recognition is given to several agencies and in particular to the key informants from the refugee community who participated in the experts panel: Alla Rybing, homemaker from Tajikistan; Inna Kaliakin, Mills Jr. High School; Natalie Wasilevsky, Salud Clinic, East Yolo Health Services; Larisa Sasson, Jewish Family Services; Mikhail Zarivny, World Relief; Olga Zaremba, American River College; Seregee Shkurkin, Broderich
Christian Center; Tanya Rybin, Soviet Health Project, Lutheran Social Services; Yelena Lipskaya, YWCA-WIC Program; and Yekaterina Zaremba, homemaker from the Ukraine.

The support provided by Barbara Schneeman, Dean, College of Agriculture and Environmental Sciences, UC Davis, Carl Keen, Chairman, Nutrition Department, UC Davis, and Nicelma King, Director, Cooperative Extension, Northern Region, was invaluable in the completion of this study.

\section{References}

Blanksteen J. 1974. Nothing beets borsch. New York: Atheneum.

Chamberlain L. 1982. The food and cooking of Russia. New York: Penguin Books.

Deutsch R. 1986. The food revolution in the Soviet Union and Eastern Europe. Boulder, CO: Westview Press Inc.

Gould-Marks M. 1963. Eating the Russian way. San Francisco: Holt Rinehart and Winston.

Kropotkin A. 1993. The best of Russian cooking. New York: Hyppocrene Books.

Lih L. 1990. Bread and authority in Russia, 1914-1921. Los Angeles: University of California Press.

Norman B. 1967. The Russian cookbook. New York: Bantam Books.

Romero-Gwynn E, Nicholson $Y$, Gwynn D, et al. 1994. Dietary patterns of people from the former Soviet Union living in Sacramento: an exploratory study. Escondido, CA: California Center for Applied Research.

Romero-Gwynn E, Nicholson $Y$, Gwynn D, et al. 1997. Dietary patterns of refugees from the former Soviet Union. Nutrition Today 32:153-6.

Sacharow A. 1989. Classic Russian cuisine. New York: Arcade Publishing.

Smith R, Christian D. 1984. Bread and salt: a social and economic history of food and drink in Russia. Cambridge, England: Cambridge University Press.

Toomore J. 1992. Classic Russian cooking. Bloomington: Indiana Press.

Uvezian S. 1976. Best foods of Russia. New York: Harcourt Brace Jovanovich. 